\title{
Virtualy Program for Stroke Rehabilitation - A Review
}

\author{
Shobha Keswani, Sumit Kalra, Rohit Chawla and Nidhi Malik* \\ Department of Physiotherapy and Rehabilitation, Max Superspeciality Hospital, India
}

Submission: May 11, 2018; Published: October 23, 2018

*Corresponding author: Nidhi Malik, Department of Physiotherapy and Rehabilitation, Max Superspeciality Hospital, Saket, New Delhi, India, Email: nidhiksmalik@gmail.com

\begin{abstract}
Stroke is one of the leading causes for disability worldwide. Motor function deficits due to stroke affects the patient's mobility and contribute to overall quality of life. Neurorehabilitation training is the most effective way to reduce motor impairments in stroke patients. Conventional rehabilitation found to provide modest and sometimes delayed effects. This systematic review focuses on the impact of Virtual Reality Program on motor rehabilitation of stroke patients. The studies suggested that virtual reality is relatively recent approach that may enable practice of functional tasks at higher dosage than traditional therapies. From this review of literature, it can be concluded that Virtual Reality is effective in improving motor functions following stroke. Use of Virtual Reality as an adjunct to conventional therapy resulted in greater motor gains than conventional therapy alone. The studies included in this review show optimal level of evidence and grade of recommendations, but further studies with larger sample sizes are needed to draw more reliable conclusion.
\end{abstract}

\section{Introduction}

Stroke is classically characterized as a neurological deficit attributed to an acute focal injury of the central nervous system (CNS) by a vascular cause, cerebral infarction, intracerebral haemorrhage (ICH), and subarachnoid haemorrhage ( $\mathrm{SAH})$, and is a major cause of disability and death worldwide [1]. Stroke affects about 17 million people per year worldwide, with an increasing rate every year [2]. Stroke survivors often suffer from physical and mental disabilities, heavily impacting their quality of life. Five years after the first stroke, nearly $66 \%$ of patients exhibit different degrees of disability and only $34 \%$ are functionally independent in their activities of daily living [3]. Stroke is a disorder associated with long term disability and is more common in older people [4]. The symptoms of stroke such as cognitive, motor and emotional sequelae often impact on a person's level of independence and quality of life [5]. The purpose of neurological rehabilitations is to promote a rapid recovery from the manifold post-stroke deficits and the attainment of a lifestyle, as close as possible to the premorbid state [6].

Motor dysfunction is the most prevalent impairment, with 9 out of 10 stroke survivors suffering from some form of upper limb motor disability [7]. Thus, there is a strong need for rehabilitative approaches enhancing motor recovery for stroke patients [8]. To maximize neural, motor and functional recovery, training needs to be long lasting, challenging, repetitive, task-specific, motivating, salient, and intensive [9]. Further approaches include strength training, trunk restraint, somatosensory training, constraintinduced movement therapy, bilateral arm training, coordination of reach to grasp, mirror training, action observation and neuromuscular electrical stimulation [10].
Virtual Reality is a relatively recent approach that may enable simulated practice of functional at a higher dosage than traditional therapies [11]. It is a computer technology that simulates real-life learning while providing augmented feedback and a high intensity of massed practiced tasks [12]. VR can be differentiated into immersive and nonimmersive gaming systems. Immersive systems enable players to move an avatar in a simulated environment. Nonimmersive systems often focus on arm or leg movements in simulated 3D environments [13]. Virtual reality immersion techniques are based on the conjunct use of a computer-generated three-dimensional graphical environments and visual, auditory, or haptic devices [14-16].

\section{Review of Literature}

Turolla et al., (2013) did a research on 367 patients divided into two groups to compare the effectiveness of virtual reality program combined with conventional therapies to conventional therapy alone and concluded that association of virtual reality-based rehabilitation with traditional restorative approaches improve the effectiveness of restoring upper limb functions [17]. Hatem et al., (2016) conducted a multiple systematic review also concluded that virtual reality is one of the approaches recommended as adjuvant therapy in improving upper limb motor functions [18]. Association of VR with traditional restorative approaches improves the effectiveness of rehabilitation of motor functions and ADL capacities compared with conventional rehabilitation alone $[19,20]$.

In a study done by Perez Marcos et al., (2017), the feasibility of training intensity in chronic stroke patient using embodied virtual 


\section{Journal of Yoga and Physiotherapy}

reality system is investigated over 10 stroke patients with upper extremity paresis. It was concluded that task specific virtual reality training may be beneficial for functional recovery in chronic stage of stroke [21]. Another study done by Schuster-Amft C. et al., (2015) to evaluate feasibility and neurophysiological changes after virtual reality-based training of upper limb movements concluded that it is feasible, safe and intense and were related to changed cortical activation patterns [22].

A review done by Maureen K. Holden et al., (2005), on Virtual Reality for motor rehabilitation. He compared motor learning in real environment than in virtual environment. As a result people with disabilities appear capable of motor learning within virtual environment [23].

In a study done by Calabrò R S et al. (2015), on the role of virtual reality in improving Motor performance revealed by EEG, it was concluded that robotic based rehabilitation combined with Virtual Reality in chronic hemiparesis induced an improvement in gait and balance [24]. Another study done by Jang et al., (2005), to investigate the effects of Virtual Reality on cortical reorganisation and motor recovery Virtual reality induces neuroplastic changes associated with motor recovery [25].

According to the study done by Krichevets et al. (1995) on virtual reality and computer gaming as a means of movement rehabilitation, it was stated that because of playful aspect of the training, subjects tends to be more motivated in VR settings than in conventional rehabilitation settings. It also improves patient motivation and confidence through reinforcement and immediate feedback, and positivity through achievement and social interaction [26].

Various studies concluded that novel demonstration of VR induces neuroplastic changes and associated motor recovery in stroke patients allows for mass practice and provide training in environments that are sometimes impractical to create in natural world [22,27-29]. VR technology can be used to produce an environment in which intensity of practice and feedback on performance can be manipulated to provide tailored motor training [30-40].

\section{Conclusion}

Based on sufficient amount of evidence, it can be concluded that virtual reality program for stroke rehabilitation is effective in improving motor functions by increasing subject interest and rate of participation, which influences brain reorganization and increases neural plasticity and eventually fastens functional recovery [41-45]. Use of virtual reality as an adjunct to conventional therapy, resulted in significantly greater motor gains than conventional therapy alone. VR is advantageous as it offers goal-oriented task, repetition and training in complex environments that are impractical to create in the natural world shown to be important in neurological rehabilitation [46-50].

\section{References}

1. Ralph L Sacco, Scott E Kasner, Joseph P Broderick (2013) l on behalf of the American Heart Association Stroke Council Stroke 44: 2064-2089.
2. Mozaffarian D, Benjamin EJ, Go AS, Arnett DK, Blaha MJ, et al. (2016) Heart disease and strokeStatistics2016 update: a report from the American Heart Association. Circulation 133: e38-e60.

3. Wilkinson PR, Wolfe CD, Warburton FG, Rudd AG, Howard RS, et al (1997) A long-term follow-up of stroke patients. Stroke 28: 507-512.

4. Donnan GA, Fisher M, Macleod M, Davis SM (2008) Stroke. The Lancet 371: $1612-1623$.

5. Hochstenbach J, Prigatano G, Mulder T (2005) Patients' and relatives' reports of disturbances 9 months after stroke: subjective changes in physical functioning, cognition, emotion, and behavior. Arch Phys Med Rehabil 86: 1587-1593.

6. Kaplan PE, Cailliet R, Kaplan CP (2003) Rehabilitation of stroke ( $1^{\text {st }}$ edn), Butterworth-Heinemann, Burlington, USA.

7. Parker VM, Wade DT, Langton HR (1986) Loss of arm function after stroke: measurement, frequency, and recovery. Int Rehabil Med 8(2): 69-73.

8. Weinstein CJ, Stein J, Arena R (2016) Guidelines for adult stroke rehabilitation and recovery: a guideline for healthcare professionals from the American Heart Association/American Stroke Association. Stroke 47(6): e98-e169.

9. Kleim JA, Jones TA (2008) Principles of experience-dependent neural plasticity: implications for rehabilitation after brain damage. J Speech Lang Hear Res 51: S225-S239.

10. Ward N (2015) Treatment of arm and hand dysfunction after CNS damage. In: Dietz V, Ward NS (Eds.), Oxford Textbook of Neurorehabilitation. Oxford, UK, pp. 238-250.

11. Kwakkel G, Van Peppen R, Wagenaar R, Wood Dauphinee S, Richards C, et al. (2004) Effects of augmented exercise therapy time after stroke. A meta-analysis. Stroke 35: 1-11.

12. Sisto SA, Forrest GF, Glendinning D (2002) Virtual reality applications for motor rehabilitation after stroke. Top Stroke Rehabil 8(4): 11-23.

13. Lange B, Koenig S, Chang CY (2012) Designing informed game-based rehabilitation tasks leveraging advances in virtual reality. Disabil Rehabil 34(22): 1863-1870.

14. Riva G (2003) Virtual environments in clinical psychology. Psychotherapy 40: 68.

15. Sivan M, O Connor RJ, Makower S, Levesley M, Bhakta B (2011) Systematic review of outcome measures used in the evaluation of robot-assisted upper limb exercise in stroke. J Rehabil Med 43: 181189.

16. Oujamaa L, Relave I, Froger J (2009) Rehabilitation of arm function after stroke. Literature review. Ann Phys Rehabil Med 52: 269-293.

17. Turolla A, Dam M, Ventura L, Tonin P (2013) Virtual reality for the rehabilitation of the upper limb motor function after stroke: A prospective controlled trial. Journal of Neuro Engineering and Rehabilitation 10(1): 85.

18. Lee SJ, Chun MH (2014) Combination transcranial direct current stimulations and virtual reality therapy for upper extremity training in patients with subacute stroke. Arch Phys Med Rehabil 95: 431-438.

19. Laver K, George S, Thomas S (2015) Virtual reality for stroke rehabilitation: an abridged version of a Cochrane review. Eur J Phys Rehabil Med 51(4): 497-506.

20. Sang Mi Jung, Won Ho Choi (2017) Effects of virtual reality intervention on upper limb motor function and activity of daily living in patients with lesions in different regions of the brain. J Phys Ther Science 29(12): 2103-2106.

21. Daniel Perez Marcos, Odile Chevalley (2017) Increasing upper limb training intensity in chronic stroke using embodied virtual reality: a pilot study Journal of Neuro Engineering and Rehabilitation 14: 119. 


\section{Journal of Yoga and Physiotherapy}

22. Schuster Amft Corina, Henneke Andrea, Hartog Keisker, Birgit, Holper, et al. (2015) Intensive virtual reality-based training for upper limb motor function in chronic stroke: a feasibility study using a single case experimental design and fMRI. Disability \& Rehabilitation: Assistive Technology 10(5): 385-392.

23. Maureen K Holden (2005) Virtual environments for motor rehabilitation: review. Cyberpsychology Behav 8(3): 207.

24. Calabrò RS, Naro A, Russo M, Leo A, De Luca R, et al. (2017) The role of virtual reality in improving motor performance as revealed by EEG: a randomized clinical trial. J Neuroeng Rehabil 14(1): 53.

25. Jang SH, You SH, Hallett M, Cho YW, Park CM, et al. (2005). Cortical reorganization and associated functional motor recovery after virtual reality in patients with chronic stroke: an experimenter-blind preliminary study. Arch Phys Med Rehabil 86: 2218-2223.

26. Krichevets AN, Sirotkina EB, Yevsevicheva IV, Zeldin LM (1995) Computer games as a means of movement rehabilitation. Disabil Rehabil 17(2): 100-105.

27. Richard J Adams, Matthew D Lichter, Allison Ellington (2018) Virtual Activities of Daily Living for Recovery of Upper Extremity Motor Function IEEE Transactions on Neural Systems and Rehabilitation Engineering 26(1): 252-260.

28. Cameirão MS, Badia SB, Duarte E, Frisoli A, Verschure PFMJ (2012) The combined impact of virtual reality neurorehabilitation and its interfaces on upper extremity functional recovery in patients with chronic stroke. Stroke 43: 2720-2728.

29. Boian R, Sharma A, Han C, Merians A, Burdea G, et al. (2002) Poizner Virtual reality-based post-stroke hand rehabilitation Stud Health Technol Inform 85: 64-70.

30. Merians AS, Jack D, Boian R, Tremaine M, Burdea GC, et al. (2002) Virtual reality-augmented rehabilitation for patients following stroke. Phys Ther 82: 898-915.

31. Townsend N, Wickramasinghe $\mathrm{K}$, Bhatnagar P, Smolina K, Nicho M (2012) Coronary heart disease statistics 2012 edition. British Heart Foundation, London, England.

32. Ng YS, Stein J, Ning M, Black Schaffer RM (2007) Comparison of clinica characteristics and functional outcomes of ischemic stroke in different vascular territories. Stroke 38(8): 2309-2314.

33. Balaban B, Tok F, Yavuz F, Yasar E, Alaca R (2011) Early rehabilitation outcome in patients with middle cerebral artery stroke. Neurosci Lett 498 (3): 204-207.

34. Davidoff RA (1990) The pyramidal tract. Neurology 40: 332-339.

35. Bobath B (1990) Adult Hemiplegia: Evaluation and Treatment, $\left(3^{\text {rd }}\right.$ edn), Heinemann Medical Books, Oxford, UK.
36. Ada L, Canning C (1990) Anticipating and avoiding muscle shortening in Key Issues in Neurological Physiotherapy, Butterworth-Heinemann, Oxford, UK, pp. 219-236.

37. Mudie MH, Matyas TA (1996) Upper extremity retraining following stroke: Effects of Bilateral Practice. Neurorehabil. Neural Repair 10: 167-184.

38. Morris DM, Taub E, Mark VW (2006) Constraint-induced movement therapy: characterizing the intervention protocol. Eura Medicophys 42: 257-268.

39. Stefan K, Kunesch E, Cohen LG, Benecke R, Classen J, et al. (2000) Induction of plasticity in the human motor corte by paired associative stimulation. Brain 123: 572-584

40. Altschuler EL, Wisdom SB, Stone L, Foster C, Galasko D, et al. (1999) Rehabilitation of hemiparesis after stroke with a mirror. Lancet 353 (9169): 2035-2036.

41. Ramachandran VS, Rogers-Ramachandran D, Cobb S (1995) Touching the phantom limb. Nature 377: 489-490.

42. Oujamaa L, Relave I, Froger J, Mottet D, Pelissier JY (2009) Rehabilitation of arm function after stroke. Literature review. Ann Phys Rehabil Med 52(3): 269-293

43. Pignolo L (2009) Robotics in neuro-rehabilitation. J Rehabil Med 41: 955-960.

44. Stefan K, Kunesch E, Cohen LG, Benecke R, Classen J (2000) Induction of plasticity in the human motor corte by paired associative stimulation. Brain 123: 572-584

45. Sergei V Adamovich, Gerard G Fluet, Eugene Tunik, Alma S Merians (2009) Sensorimotor Training in Virtual Reality: A Review. Neurorehabilitation 25(1): 29-44.

46. Iris Brunner, Jan Sture Skouen, Håkon Hofstad (2016) Is upper limb virtual reality training more intensive than conventional training for patients in the subacute phase after stroke? An analysis of treatment intensity and content. BMC Neurology 16: 219.

47. Saposnik G, Levin M (2011) Virtual reality in stroke rehabilitation: a meta-analysis and implications for clinicians. Stroke 42: 1380-1386.

48. Fitzgerald SG, Cooper RA, Thorman T, Cooper R, Guo S, et al. (2004) The game(cycle) exercise system: comparison with standard ergometry. J Spinal Cord Med 27: 453-459.

49. Laver KE, George S, Thomas S, Deutsch JE (2011) Virtual reality for stroke rehabilitation. Cochrane Database Syst Rev 9: CD008349.

50. Rachel C Stockley, Deborah AO Connor (2017) Mixed Methods Small Pilot Study to Describe the Effects of Upper Limb Training Using a Virtual Reality Gaming System in People with Chronic Stroke. Rehabil Res Pract 1-8.

\section{Your next submission with Juniper Publishers} will reach you the below assets

- Quality Editorial service

- Swift Peer Review

- Reprints availability

- E-prints Service

- Manuscript Podcast for convenient understanding

- Global attainment for your research

- Manuscript accessibility in different formats

(Pdf, E-pub, Full Text, Audio)

- Unceasing customer service

Track the below URL for one-step submission https://juniperpublishers.com/online-submission.php 